\title{
MOTIF KECURANGAN, ADANYA KESEMPATAN DAN MANIPULASI LABA
}

\begin{abstract}
This research examines the relationship between fraud motives (leverage and dividends) and earnings manipulation; and the relationship between opportunities (quality audit and free cash flow) and earnings manipulation. This research used a sample of 24 companies listed on the Indonesia Stock Exchange in 2011-2013. The results of this research analysis is that there is a significant negative correlation between dividend payments and earnings manipulation. This research also proved that free cash flow has a positive correlation with earnings manipulation.
\end{abstract}

Keywords: earnings manipulation, leverage, dividend, quality audit and free cash flow.

\section{PENDAHULUAN}

Manipulasi laba merupakan teknik yang digunakan oleh manajemen perusahaan untuk sengaja mempengaruhi angka laba sesuai dengan kepentingan manajemen. Informasi laba dalam laporan keuangan merupakan informasi yang penting untuk menunjukkan kinerja perusahaan. Informasi laba digunakan oleh investor dalam mengambil keputusan akan berinvestasi. Dengan demikian informasi laba merupakan elemen penting dalam menentukan nilai perusahaan dalam pasar saham. Dikarenakan informasi laba berpengaruh terhadap reaksi pasar maka manajemen perusahaan akan berusaha untuk memanipulasi laba untuk kepentingan pribadi manajer.

Agency Theory menjelaskan konflik kepentingan antara manajemen perusahaan dan investor. Tekanan tidak hanya muncul dari investor melainkan terdapat faktor lain sehingga manajemen perusahaan melakukan manipulasi laba. Faktor tersebut antar lain kepentingan untuk memperoleh dana dari kreditur, kewajiban dalam kontrak antara manajemen perusahaan dan pihak lain, pasar saham yang bergejolak, bonus pribadi, promosi dan menyembunyikan transaksi yang melanggar hukum (Duncan, 2001). Motivasi manajer bertindak opotunis dapat dijelaskan dengan teori akuntansi positif yaitu bonus plan hypothesis, debt covenant hypothesis dan political cost hypothesis (Watts dan Zimmerman 1990).

Putri (2012) dalam penelitiannya mengemukakan bahwa kebijakan dividen berpengaruh secara signifikan terhadap manajemen laba. Beatty dan Weber (2003), Dichev dan Skinner (2002), DeFond dan Jiambalvo (1994) dan Sweeney (1994) yang menemukan bahwa perusahaan dengan leverage yang tinggi terlibat dalam manajemen laba untuk menghindari perjanjian utang oleh lembaga keuangan. Sedangkan Jao dan Pagalung (2011) dalam penelitiannya menjelaskan bahwa leverage tidak mempengaruhi manajemen laba. Christiani dan Nugrahanti (2014) menemukan bahwa kualitas audit tidak berpengaruh terhadap manajemen laba. Tujuan dari penelitian ini adalah menganalisis hubungan antara motif kecurangan (leverage dan dividen) dan manipulasi laba; dan hubungan antara kesempatan (kualitas audit dan free cash flow) dan manipulasi laba pada perusahaan manufaktur yang terdaftar di Bursa Efek Indonesia. 


\section{KERANGKA TEORITIS DAN PENGEMBANGAN HIPOTESIS}

Penelitian ini menganalisis mekanisme eksternal melalui peran berbagai pihak seperti pemegang saham, kreditur, dan auditor. Penelitian ini menganalisis bagaimana motif dan kesempatan berhungan dengan manipulasi laba. Empat hipotesis dikembangkan pada penelitian.

\section{Hubungan antara deviden dan manipulasi laba}

Dividen dan nilai perusahaan telah diteliti oleh Miller dan Rock (1985). Hasil penelitian membuktikan bahwa dividen digunakan oleh perusahaan sebagai alat signaling kepada investor dan menjadi dasar dari dividen signaling theory. Frankfurter dan Wood (2002), Docking dan Koch (2005) membuktikan bahwa pengumuman pembagian deviden merupakan faktor yang mempengaruhi nilai perusahaan.

Menurut Easterbrook (1984) mengemukakan dividen yang lebih tinggi mengurangi agency cost. Agency cost berkurang diharapkan menyebabkan nilai perusahaan lebih tinggi. Jensen (1986) berpendapat bahwa dividen dapat mengurangi free cash flow yang digunakan oleh manajer untuk investasi yang kurang menguntungkan. Hal tersebut konsisten dengan gagasan bahwa dividen yang dibayarkan ketika perusahaan memiliki free cash flow dapat mengurangi potensi penyalahgunaan investasi oleh manajemen. Argumen di atas menunjukan hipotesis berikut:

H1 : pembayaran dividen memiliki hubungan negatif yang signifikan dengan manipulasi laba.

\section{Hubungan antara leverage dan manipulasi laba}

Selahudin, et.al. (2014) berpendapat bahwa peningkatan leverage akan mengurangi agency cost yang melekat dalam operasional perusahaan. Menurut Agrawal dan Knoeber (1996) pembiayaan hutang sering digunakan sebagai alternatif untuk mengurangi agency cost. Grossman dan Hart (1982) berpendapat bahwa financial leverage dapat mengurangi agency costs dengan peningkatan level kebangkrutan. Grossman dan Hart (1982) lebih lanjut menyatakan bahwa financial leverage yang besar dapat mengurangi agency costs melalui ancaman likuidasi yang mengakibatkan kerugian manajer dalam hal penghasilan dan reputasi.

Myers (1977) menjelaskan bahwa tingkat leverage yang tinggi dapat mengurangi konflik antara investor dan manajemen mengenai pilihan investasi perusahaan. Hutang dapat berfungsi sebagai mekanisme untuk mendisiplinkan manajer perusahaan dan mencegah mereka melakukan tindakan kecurangan (Jansen dan Meckling, 1986). Perusahaan yang memiliki leverage yang tinggi akan menghadapi resiko kebangkrutan jika tidak mampu membayar hutang luar negeri. Oleh karena itu berdasarkan uraian di atas dapat dikembangkan hipotesis sebagai berikut:

H2: leverage memiliki hubungan positif yng signifikan dengan manipulasi laba.

\section{Hubungan antara Audit Independence dan manipulasi laba}

Peran auditor sangat penting dalam menjaga kualitas laporan keuangan. Auditor memfasilitasi kepentingan internal dan eksternal perusahaan seperti investor, kreditur, pemerintah, karyawan, pelanggan 
dan lain-lain (Chia, Lapsley dan Lee, 2007).

DeAngelo (1981) mendefinisikan kemerdekaan dalam kerangka yang lebih luas dari kualitas audit. Kualitas audit adalah penggabungan antara auditor menemukan dan melaporkan salah saji. Independensi auditor dianggap berkurang ketika auditor gagal melaporkan salah saji yang telah ditemukan.

Penyediaan layanan non-audit dapat mengganggu tingkat independensi, karena akan muncul kepentingan ekonomi antara auditor dan manajemen perusahaan. Menurut Simunic (1984) independensi auditor akan menurun ketika menerima permintaan jasa audit dan non-audit dikarenakan keterikatan ekonomi kepada manajemen perusahaan. Parkash dan Venable (1993) menemukan bahwa perusahaan di Amerika Serikat dan Inggris cenderung meminta layanan non-audit dari auditor. Mereka menemukan bahwa perusahaan membutuhkan kualitas audit dikarenakan agency costs. Gore et. al. (2001) membuktikan bahwa penyediaan layanan non-audit memiliki hubungan positif dengan manajemen laba. Perusahaan dengan layanan non-audit lebih cenderung melakukan praktik manajemen laba. Berdasarkan uraian di atas dapat dikembangkan hipotesi sebagai berikut:

H3 : Audit Independence memiliki hubungan negatif yang signifikan dengan manipulasi lama

\section{Hubungan antara Free Cash Flow dan Manipulasi Laba}

Jensen (1986) menyatakan bahwa jika free cash flow pada perusahaan tidak digunakan atau diinvestasikan untuk kepentingan investor maka akan menimbulkan masalah keagenan. Jika manajer menggunakan free cash flow untuk investasi yang tidak menguntungkan karena kepentingan pribadi maka akan menyebabkan pertumbuhan perusahaan yang rendah. Dengan lemahnya pengawasan manajer akan cenderung menyembunyikan informasi dengan tidak memberikan sedikit pengungkapan atau memanipulasi angka akuntansi pada laporan keuangan. Berdasarkan keterbatasan informasi investor tidak dapat mengetahui kerugian atau keuntungan dari proyek untuk kepentingan mereka (Chung et. al., 2005)

Manajer tidak dapat memberikan informasi tentang proyeksi internal cash flow dari beberapa investasi yang mereka lakukan. Manajer dapat melakukan investasi untuk kepentingan pribadi. Pilihan untuk melakukan investasi yang merugikan dapat mengurangi laba dan menurunnya kredibilitas manajer perusahaan. Untuk menghindari resiko yang akan dihadapi oleh manajemen, maka manajer akan memilih melakukan manipulasi laba. Berdasarkan asumsi tersebut dapat dikembangkan hipotesis sebagai berikut:

$\mathrm{H} 4$ : Free cash flow memiliki hubungan positif yang signifikan dengan manipulasi laba.

\section{METODELOGI PENELITIAN}

\section{Populasi, Sampel dan Teknik Pengambilan Sampel}

Populasi pada penelitian ini adalah perusahaan manufaktur yang terdaftar di Bursa Efek Indonesia (BEI) periode 2011-2013. Penelitian ini menggunakan teknik purposive sampling yaitu (1) perusahaan mengalami laba berturut-turut selama periode penelitian; (2) perusahaan manufaktur yang terdaftar di BEl selama periode 2011-2013; (3) perusahaan yang menyajikan laporan tahunannya dalam website BEl selama periode 20112013; (4) laporan keuangan perusahaan memiliki data-data yang dibutuhkan; (5) perusahaan yang melaporkan 
laporan keuangan dalam mata uang rupiah. Berdasarkan hasil dari pemilihan sampel dengan kriteria tersebut sampel dalam penelitian ini sebanyak 24 perusahaan.

\section{Research Design}

Penelitian ini menggunakan Beneish M-Score untuk memdeteksi manipulasi laba. Jika perusahaan laporan keuangan terindikasi melakukan manipulasi laba bernilai "1", sedangkan perusahaan yang tidak terindikasi melakukan manipulasi laba akan bernilai "0".

$$
\begin{gathered}
\text { M-Score }=-4,84+0,92 * \mathrm{DSRI}+0,528^{*} \mathrm{GMI}+0,404 * \mathrm{AQI}+0,892 * \mathrm{SGI}+0,115^{*} \mathrm{DEPI}-0,172 * \mathrm{SGAI}+4,679 * \text { TATA }- \\
0,327^{*} \mathrm{LVGl}
\end{gathered}
$$

Keterangan:

DSRI : Day's Sales in Receivables index (Receivables / Total Sales)

GMI : Gross Margin Index (Gross Profit/Total Sales)

AQI : Asset Quality Index ((Non-Current Assets-PP\&E)/Total Assets)

SGI : Sales Growth Index (Total Sales)

DEPI : Depreciation Index (Depreciation/(Depreciation+Net PP\&E))

SGAI : SG\&A Expense Index (SG\&A/Revenues)

TATA : Total Accruals to Total Assets ((Working Capital-Cash)/Depreciation)

LVGI : Leverage Index (Total Debt/Total Assets)

Penelitian ini menggunakan regresi untuk menguji hubungan antara manipulasi laba dengan dividen, leverage, audit independence dan free cash flow.

$\mathrm{MI}=\quad \lambda_{1}+\lambda_{2}(\mathrm{LEV}) \mathrm{it}+\lambda 3(\log \mathrm{AFEE}) \mathrm{it}+\lambda 4(\log F C F) i \mathrm{t}+\lambda 5(\mathrm{DYLD}) \mathrm{it}+\lambda 6(\mathrm{ROE}) \mathrm{it}+\lambda 7(\log \mathrm{A})(\mathrm{it}+\varepsilon$ it $)$
Keterangan :
MI : Manipulation Index
LEV : Leverage; debt to total assets
LogAFEE : Auditfees
LogFCF : Free cash flow
DYLD : Dividend yield
ROE : Return on equity
TA :Total assets

\section{HASIL DAN PEMBAHASAN}

Hasil analisis regresi pada hubungan antara manipulasi laba dengan dividen, leverage, audit independence dan free cash flow periode 2011-2013 tersaji pada tabel terlampir.

Berdasarkan hasil analisis di atas menunjukkan bahwa Dividend yield,log Free Cash Flow dan log Total 
Aset memiliki hubungan negatif yang signifikan dengan manipulasi laba. Hasil tersebut mendukung hipotesis 1 yang menyatakan bahwa perusahaan yang membagikan deviden kemungkinan melakukan manipulasi laba lebih kecil. Hasil analisis juga menunjukkan bahwa mendukung hipotesis 4 yang menyatakan bahwa manajer akan lebih cenderung melakukan manipulasi laba ketika terjadi surplus free cash flow.

Variabel kontrol log Total Aset menunjukkan memiliki hubungan yang signifikan terhadap manipulasi laba. hasil tersebut konsisten dengan penelitian Keasey (1999) yang membuktikan ukuran perusahaan berpengaruh signifikan terhadap kinerja manajemen.

\section{SIMPULAN}

Hasil penelitian ini diharapkan dapat menjelaskan faktor-faktor yang memotivasi manajer melakukan manipulasi laba di Indonesia. Hasil penelitian menunjukkan bahwa pembagian deviden meminimalkan manajer melakukan manipulasi laba, serta surplus free cash flow memberi kesempatan manajer melakukan manipulasi laba. Manajer dapat melakukan manipulasi laba untuk kepentingan pribadi. Sedangkan hipotesis ke dua ditolak, hal ini bertentangan dengan penelitian Beatty dan Weber (2003), Dichev dan Skinner (2002), Sweeney (1994), dan mendukung penelitian Jao dan Pagalung (2011). Penelitian ini juga menolak hipotesis ke tiga yang menyebutkan bahwa Audit Independence memiliki hubungan negatif yang signifikan dengan manipulasi laba.

\section{DAFTAR PUSTAKA}

Agrawal, S., Knoeber, C. R. 1996. Firm Performance and Mechanisms to Control Agency Problems Between Manager and Shareholders. Journal of Financial and Quantitative Analysis, 31 (03). 377-397.

Aulia, F.R., Norman, M. S., 2008. The Effect of Free Cash Flow Agency Problem on theValue Relevance of Earnings and Book Value. Journal of Financial Reporting andAccounting, 6(1), 75 - 90

Beatty, A., Weber, J., 2003. The Effect of Debt Contracting on Voluntary Accounting Method Changes. The Accounting Review, 78(1), 119-142.

Becker, C.L., Defond, M.L., Jiambalvo, J., Subramanyam, K.R., 1998. The Effect of Audit Quality on Earnings Management. Contemporary Accounting Research, 15(1), 1-24.

Bhabra, G. S., 2007. Insider ownership and firm value in New Zealand. Journal of Multinational Financial Management 17, 142-154.

Chang, J.C., Sun, H.L., 2009. Crossed-Listed Foreign Firms'Earnings Informativeness. Earnings Management and Disclosures of Corporate Governance Information under SOX. The International Journal of Accounting, $44,1-32$.

Chia,Y. M, Lapsley, I., Lee, H. W., 2007. Choice of auditors and earnings management during the Asian financial crisis. Managerial Auditing Journal, 22(2), 177-196

Choi, J-H, Kim, C., Kim, J.B.,. Zang, Y., 2010. Audit office size, audit quality, and audit pricing. Auditing: A Journal of Practice and Theory, 29(1), 73-97. 
Chung, R., Firth, M., Kim, B.K., 2005. Earnings Management, Surplus Free Cash Flow, and External Monitoring. Journal of Business Research, 58, 766-776.

Christiani, Ingrid, Y. W. Nugrahanti. 2014. Pengaruh Kualitas Audit Terhadap Manajemen Laba. Jurnal Akuntansi dan Keuangan, Vol 16, No. 1.

Duncan, J. R. 2011. Twenty Pressures to manage earnings. The CPA Journal, 71(7), 32.

Davidson III, W.N., Jiraporn, P., Kim, Y.S., Nemec, C., 2004. Earnings Management Following Duality-Creating Successions: Ethnostatistica,Impression Management, and Agency Theory. Academy of Management Journal 47(2), 267-275

DeAngelo, L. E., 1981 b. Auditor size and audit quality. Journal of Accounting and Economics, 3 (3), 183-199.

Dechow, P.M., Sloan, R.G., Sweeney, A.P., 1995. Detecting Earnings Management. The Accounting Review, 70(2), 193-225.

DeFond, M., Jiambalvo, J., 1994. Debt Covenant Effects and the Manipulation of Accruals. Journal of Accounting and Economics, 17, 145-176.

DeFond, M.L., Raghunandan, K., Subramanyam, K.R., 2002. Do Non-audit service fees impair auditor independence? Evidence from going concern audit opinions. Journal of Accounting Research, 40(4)

Dichev, I.D., Skinner, D.J., 2002. Large-Sample Evidence on the Debt Covenant Hypothesis. Journal of Accounting Research, 40(4), 1091-1123

Docking, D.S., Koch, P.D. 2005. Sensitivity of Investor Reaction to Market Direction and Volatility: Dividend Change Announcements. Journal of Financial Research, 28(1), 21-40.

Duh, R.R., Hou, C.P., Huang, D.F., 2009. Audit Partner's General Experience, Industry Specialization, and Audit Quality. Working paper, National Taiwan University, China University of Technology, and National Dong Hwa University.

Easterbrook, F. H. 1984. Two Agency-cost Explanations of Divident. The American Economic Review. 74(4).

Firth, M. 1997, The Provision of Nonaudit Services by Accounting Firm to Their Audit Clients. Contemporary Accounting Research. 14(2).s

Frankfurter, G. M., B.G. Wood. 2002. Dividend Policy Theories and Their Empirical Tests. International Review of Financial Analysis, 11(2).

Gul, F. A., Tsui, J., 1998. A Test of the Free Cash Flow and Debt Monitoring Hypotheses: Evidence from Audit Pricing. Joumal of Accounting and Economics, 24, 219-237.

Grossman, S.J., O.D. Hart. 1982. Corporate Financial Structure and Managerial Incentives. The Economic of Information and Uncertanty (pp. 107-140). University of Chicago Press.

Healy, P.M., Wahlen, J.M., 1999. A Review of the Earnings Management Literature and Its Implications for Standard Setting. Accounting Horizons, 13(4), 365-383

Hoitash, R., Hoitash, U., Bedard, J. C., 2007. Internal Control Quality and Audit Pricing under the Sarbanes-Oxley Act. Auditing: A Journal of Practice and Theory, 27(1), 105-126.

Jao, R., G. Pagalung, 2011. Corporate Governance, Ukuran Perusahaan, dan Leverage Terhadap Manajemen Laba Perusahaan Manufaktur Indonesia. Jurnal Akuntansi dan Auditing. 
Jelinek, K., 2007. The Effect of Leverage Increases on Earnings Management. Journal of Business \& Economic Studies, 13(2), 24-26.

Jensen, M., 1986. Agency Cost and Free Cash flow, Corporate Finance, and Takeovers. American Economic Review, 76, 323-326.

Jensen, M., Meckling, W., 1976. Theory of the Firm: Managerial Behavior, Agency Costs, and Ownership Structure. Journal of Financial Economics, 3, 305-360.

Kothari, S.P., Leone, A.J.,Wasley, C.E., 2005. Performance Matched Discretionary Accruals Measures. Journal of Accounting and Economics, 39, 163-197.

Miller, M. H., Rock, K. 1985. Dividend policy under asymmetric information. The Journal of Finance, 40 (4), 10311051.

Myers, S.C., Turnbull, S. M., 1977. Capital budgeting and the capital asset pricing model: Good news and bad news. Journal of Finance, 32, 321- 333

Parkash, M., Venable, C. F., 1993. Auditee Incentives for Auditor Independence: The case of nonaudit services. Accounting Review. 113-133.

Putri, Dwija. 2012. Pengaruh Kebijakan Dividen terhadap Good Corporate Governance terhadap Manajemen Laba. Buletin Studi Ekonomi Vol. 17 No. 2

Selahudin, N.F., Zakaria, N.B., Mohd-Sanusi, Z., Budsaratragon, P., 2014. Monitoring Financial Risk Ratios and Earning Management: Evidence from Malaysia and Thailand. International Conference on Corporate Governance \& Strategic Management (ICGSM) 2014.Procedia - Social and Behavioral Sciences, 145, 51 60.

Simunic, D. A. 1984. Auditing, Consulting and Auditor Independence. Journal of Accounting Research. 679-702.

Short, H., Keasy, K., 1999. Managerial ownership and the performance of firms: evidence from the UK. Journal of Corporate Finance, 5, 79-101.

Sweeney, A.P., 1994. Debt Covenant Violations and Managers' Accounting Responses. Journal of Accounting and Economics, 17(3), 281-308.

Watts, R.L. Zimmerman, J.L., 1990. Positive Accounting Theory: A Ten Year Perspective. The Accounting Review, 65, 131-156. 


\section{Lampiran}

Tabel 1. F Test Result

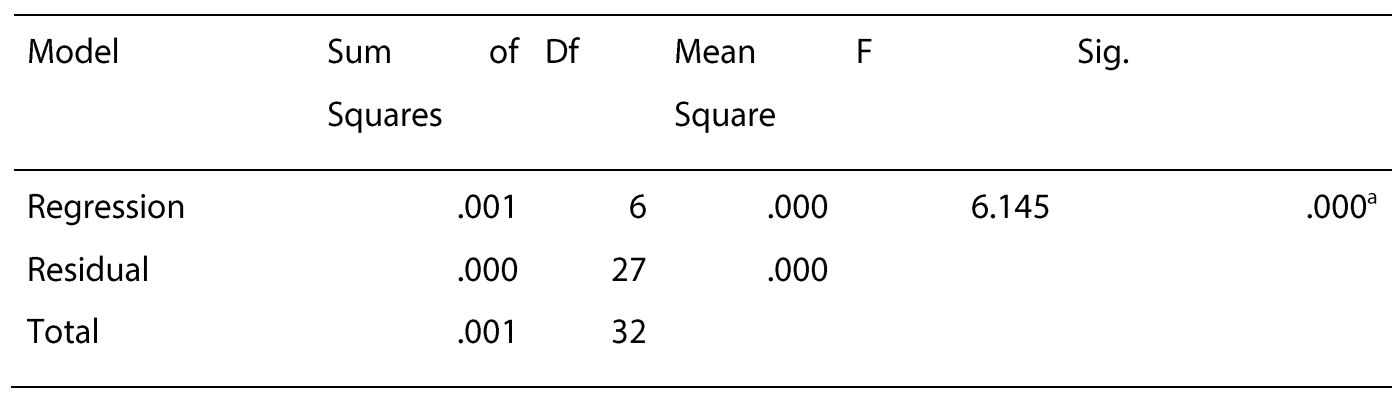

a. Predictors: (Constant), MI, LEV, LogAFEE, LogFCF, DYLD, ROE, LogTA

\section{Tabel 2.t Test Result}

\begin{tabular}{|c|c|c|c|c|c|}
\hline \multirow[t]{2}{*}{ Model } & \multicolumn{2}{|c|}{$\begin{array}{l}\text { Unstandardized } \\
\text { Coefficients }\end{array}$} & \multirow{2}{*}{$\begin{array}{c}\text { Standardized } \\
\text { Coefficients } \\
\text { Beta }\end{array}$} & \multirow[t]{2}{*}{$\mathrm{T}$} & \multirow[t]{2}{*}{ Sig. } \\
\hline & B & Std. Error & & & \\
\hline 1. (Constant) & .124 & .064 & & 2181 & .030 \\
\hline LEV & .026 & .024 & .058 & .762 & .448 \\
\hline LogAFEE & .004 & .008 & .036 & .346 & .736 \\
\hline LogFCF & .002 & .001 & -.126 & -1.864 & .003 \\
\hline DYLD & -.001 & .001 & -.052 & -1.765 & .005 \\
\hline ROE & .000 & .000 & -.058 & -.786 & .414 \\
\hline LogTA & -.009 & .004 & -.178 & -1.678 & .008 \\
\hline
\end{tabular}

